\title{
Thunderstorm and Lightning: the Temperature Effect on Climate Change of Rangpur Region in Bangladesh
}

\author{
Bakul Kumar Chakravorti ${ }^{1, ~ *, ~ P r o s a n n a j i d ~ S a r k a r ², ~ A t i u r ~ R a h m a n ~}{ }^{3}$, Atikur Rahman $^{4}$ \\ ${ }^{1}$ Department of Physics, Begum Rokeya University, Rangpur, Bangladesh \\ ${ }^{2}$ International Research and Training Institute, Begum Rokeya University, Rangpur, Bangladesh \\ ${ }^{3}$ Department of Geography and Environmental Science, Begum Rokeya University, Rangpur, Bangladesh \\ ${ }^{4}$ Main Meteorological Office, Chittagong Airport, Chittagong, Bangladesh
}

Email address:

bkcb59@gmail.com(B.K. Chakravorti)

${ }^{*}$ Corresponding author

\section{To cite this article:}

Bakul Kumar Chakravorti, Prosannajid Sarkar, Atiur Rahman, Atikur Rahman. Thunderstorm and Lightning: the Temperature Effect on Climate Change of Rangpur Region in Bangladesh. Science Journal of Energy Engineering. Vol. 6, No. 2, 2018, pp. 31-36.

doi: $10.11648 /$ j.sjee.20180602.11

Received: February 20, 2018; Accepted: March 11, 2018; Published: April 18, 2018

\begin{abstract}
Thunderstorm and lightning are the burning issues in present. Raising temperature badly affects on the environmental balance. We have collected data and studied the temperature variation and the temperature effect on the environment and on the people of Rangpur (divisional city of Bangladesh) region. Increase of monthly maximum temperature is $0.60^{\circ} \mathrm{C}$, monthly minimum temp is $1.39^{\circ} \mathrm{C}$ and monthly mean temperature of Bangladesh is $0.79^{\circ} \mathrm{C}$ per 100 years [1] where in last 29 (1984-2013) years the temperature of Rangpur station is increased almost $1.2^{\circ} \mathrm{C}$. [2] Thunderstorm and lightning occur for this increased temperature. We also analyzed the number of occurrences of thunderstorm in last ten years. We tried to find out some way to reduce the temperature increase and to safe the people. We constructed earthen in five multi-stored buildings and observed the lightening effect on and around of these buildings in last ten years.
\end{abstract}

Keywords: Thunderstorm, Lightning, Temperature, Rangpur

\section{Introduction}

Geographically Bangladesh is located in the region between $20.35^{\circ} \mathrm{N}$ to $26.75^{\circ} \mathrm{N}$ latitude and $88.03^{\circ} \mathrm{E}$ to $92.75^{\circ} \mathrm{E}$ longitude which is the indicated zone of natural disaster like storm, drought, flood etc. [3] The abovementioned types of disasters make the problems all the more complicated. In the foreseeable future, Bangladesh is likely to be one of the most vulnerable countries of the world in the event of climate change. [4] Last few years Bangladesh experienced a new disaster lightening. Naturally occurred (though sometimes people are responsible from various prospects) this lightening causes a countable death of human and other animals in every season. Bangladesh is suffering with a long term climate change (In last 25years average temperature of Bangladesh increased by $1.5^{\circ} \mathrm{C}$ ). To fulfill the fundamental demand of increasing population (through growth rate of population is decreasing with time that we deserve) in a limited land area of the country. People are constructing their houses, apartments, industrial areas, amusement parks, educational institutions, health care centers etc. by filing the cultivable lands, ponds, rivers, lakes as well as play ground of schools and colleges etc. People are cutting different types of trees to manage their accommodations and daily necessities that are responsible for deforestation. Due to decreasing number of trees (trees maintain the temperature for our healthy living) temperature of our land area is increasing. In addition, people are using various kinds of vehicle for their transportation. These numbers of increasing vehicles extracts a huge amount of carbon di-oxide $\left(\mathrm{CO}_{2}\right)$, carbon mono-oxide (CO), and sulphur (S) gases that are very much harmful for our weather and this changing weather is also responsible for long term climate change. These gases affected the ozone layer and ultraviolet rays come to the 
ground easily. In last few years, temperature is changed drastically that is very much threatening for our daily life. The rapid expansion of heated air causes the thunder. We live in the earth's environment which is constantly electrified. The knowledge of this important property of the atmosphere was truly sought only from the observation of a flash of lightning from a thundercloud. Otherwise, in the absence of a flash, in fair weather condition, it is nearly impossible to know that the earth's atmosphere is filled with electric currents. [5] Furthermore, the evaporation system is not conducting in proper way since the water sources are reducing day by day for various purposes. Thus the cycle of evaporation system, and cloud formation are interrupted and the raining is not in regular basis. For lack of cloud formation, thunder storm and lightening occurs instead of heavy raining. Clouds are getting huge space to move and charged particles collide with the high speed and as a result, lightening occurs. Basically, the number of premature death due to lightening is increasing over the time. Normally, in summer season (Month of May and June) the number of occurring lightening cooperatively increased and the percentages of death by lightning are dangerously increasing in the last few years in Bangladesh. Its' physical characteristics include current levels sometimes in excess of $400 \mathrm{kA}$, temperatures to 50,000 degrees F., and speeds approaching one third the speed of light. Globally, some 2000 on-going thunderstorms because about 100 lightening strikes to earth each second. The people of our country are facing thus a natural disaster named lightning. Lightning disaster has caused billions of dollars of property and infrastructure damages, unexpected disruption to socioeconomic activities, crops, live stocks and tragic loss of human beings each year. [6, 7] Strong thunderstorms also produced tornadoes, which can cause massive destruction to personal and business property. Thunderstorms occurred when warm, moist air within a rain cloud, rises in large volumes and with increasing velocity. Similar result was also supported by (NSSL, 2008). [8]

\section{Objectives of the Study}

i) To analyze the number of occurrences of thunderstorm in last ten years.

ii) To construct earthen in some multi-stored buildings and to observe the lightning effect on and around of these buildings in last ten years.

iii) To identify the factors affecting awareness level of people about thunderstorm and lightening.

iv) To find out some way to reduce the temperature increase and to safe the people.

v) To formulate future plan on thunderstorm and lightening.

\section{Methodology}

This study is based on primary and secondary data. A set of earthen were established on the roof top of several multistoried buildings in the different corners of Rangpur city. Primary data are collected from five multi-stored buildings in and around Rangpur and observed the lightning effect on and around of these buildings in last ten years $\left(25^{\text {st }}\right.$ February, 2008 to $24^{\text {th }}$ February, 2017) and secondary data are collected from meteorological office, Rangpur, Bangladesh as well as from related journals and books for this study. To perform the analysis on the data sets and to derive the findings, surveillance analysis along with usual descriptive statistical tools and techniques has been applied in the study.

\subsection{Rationale of the Study}

Rangpur, the northern part of Bangladesh, is the most vulnerable region in our country. Rangpur is the core of this northern part which holds the densest population. People are usually habitual with drought, flood, malnutrition etc. Most of the people depend on agriculture. They work in cultivable lands and crops fields mostly in summer and rainy seasons. In summer, farmers cut their paddy and other crops in their agricultural field. In addition, temperature remains hot enough due to hot sunny day. The temperature drastically fluctuates from noon to evening. Due to lack of cloud formation in this time a countable number of thunderstorms occur than rain. As a result people, students of different types of institutions, cattle, animals etc. die in premature death. Moreover, different types of home appliances like television, fridge, microwave woven, air cooler machine, and computer get damage as well as burn also. Farmers contribute strongly to the national economy and development of the nation. Students are the backbone of any prominent country. Animals, cattle and trees are very essential elements of our safe and healthy environment. To save the people and other environmental essential animals with different types of tree, it is mandatory to keep the temperature increase in a desired level because of the increasing temperature causes anomaly in natural weather and badly affects to the people and school going children and others. We establish earthen in five multistored buildings in the different rural and urban area of Rangpur to grow awareness to the people about and to save the people from thunderstorm and lightening.

\subsection{Formation of Lightning}

The rapid expansion of heated air causes the thunder. Since light travels faster than sound, the thunder is heard after the lightning. A moving thunderstorm gathers positively charged particles along the ground that travel with the storm. As the differences in charges continue to increase, positively charged particles rise up tall objects such as trees, houses, and telephone poles and people. The negatively charged bottom part of the storm sends out an invisible charge toward the ground. When the charge gets close to the ground, it is attracted by all the positively charged objects, and a channel develops. The subsequent electrical transfer in the channel is lightning. Not all lightning forms in the negatively charged area low in the thunderstorm cloud. Some lightning 
originates in the top of the thunderstorm, the area carrying a large positive charge. Lightning from this area is called positive lightning. Positive lightning is particularly dangerous, because it frequently strikes away from the rain core, either ahead or behind the thunderstorm. It can strike as far as 5 or 10 miles ( 8 or 16 kilometers) from the storm, in areas that most people do not consider to be a lightning-risk area Furthermore, during a thunderstorm, each flash of cloudto-ground lightning is a potential killer. The determining factor on whether a particular flash could be deadly depends on whether a person is in the path of the lightning discharge. The visible flash that travels through the air, the current associated with the lightning discharge travels along the ground. Although some victims are struck directly by the main lightning stroke, many victims are struck as the current moves in and along the ground. Ground current strikes affect a much larger area than the other causes of lightning casualties, the current travels over the surface of the ground; this type causes the most lightning deaths and injuries. It's especially bad for livestock. Earthen is the most effective way to save life and others from this lightening.

The grounding plane:

1. The best grounding planes are:

a) Copper or copper clad ground rods driven into the earth

b) Copper water pipes or other building grounds, such as metal structural frame

c) Metal enclosures and casings (which in turn should be grounded to earth ground)

2. Grounding rods should be either copper or galvanized steel, and have a minimum diameter of 5/8 inch.

3. Aluminum should not be used in direct soil burial as a grounding rod since the alkalinity of the soil will etch the metal. This causes disconnection and an increase in impendence between the grounding system and earth ground.

\subsection{The Grounding Wire}

(1) Used heavy wire gauges (10 AWG or larger) for running the grounding wire. This is important as a thicker wire gauge, along with a short cable, runs the impendence of the grounding wire lower, keeping voltage drops during surges to a minimum. (2) The cable can be either solid or stranded (just as long as it is a heavy-enough wire gauge). The wire can be either bare or insulated.

\subsection{Blessing of Thunderstorm}

Thunderstorms also produce sizable benefits to the environment and economy. One of their major blessings is the production of copious rainfall worth billions of dollars to the economy. Lightning converts gaseous nitrogen into compounds essential to plants, and lightning fixation accounts for $20 \%$ of the global total nitrogen deposited. Storms also maintain the global electrical circuit, transferring electrical charge from the atmosphere to the earth. Thunderstorms also play a significant role in the atmosphere's compositions with updrafts transporting pollutants a lot and storm rainfall scavenging vast amounts of pollutants in the air. [9] Periods of continuous rain over a few days were generally characterised by a fall in the wet bulb temperature with a corresponding decrease in lightning activity. [10]

\section{Results}

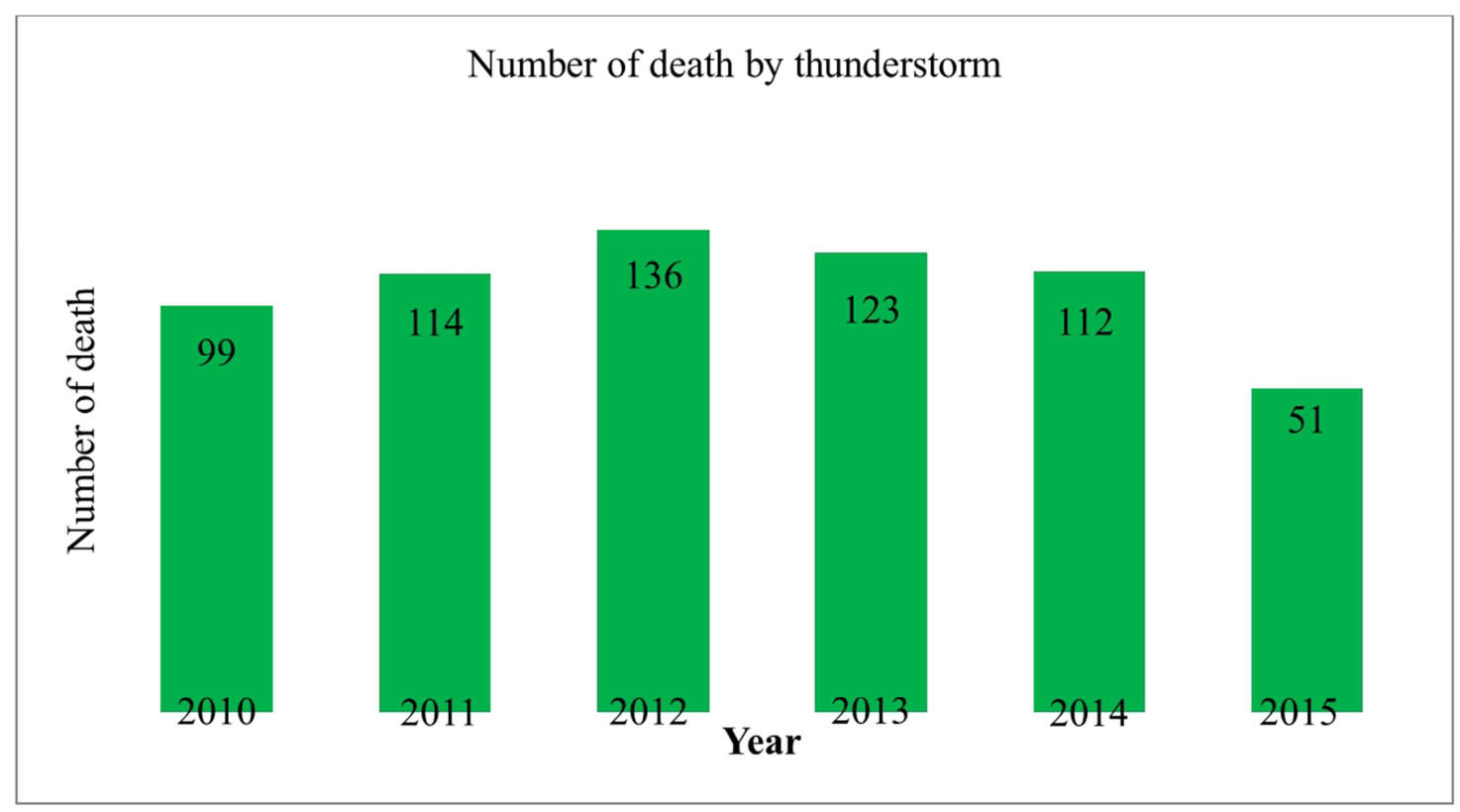

Source: The daily star reports (2010-2015)

Figure 1. Number of death by thunderstorm. 


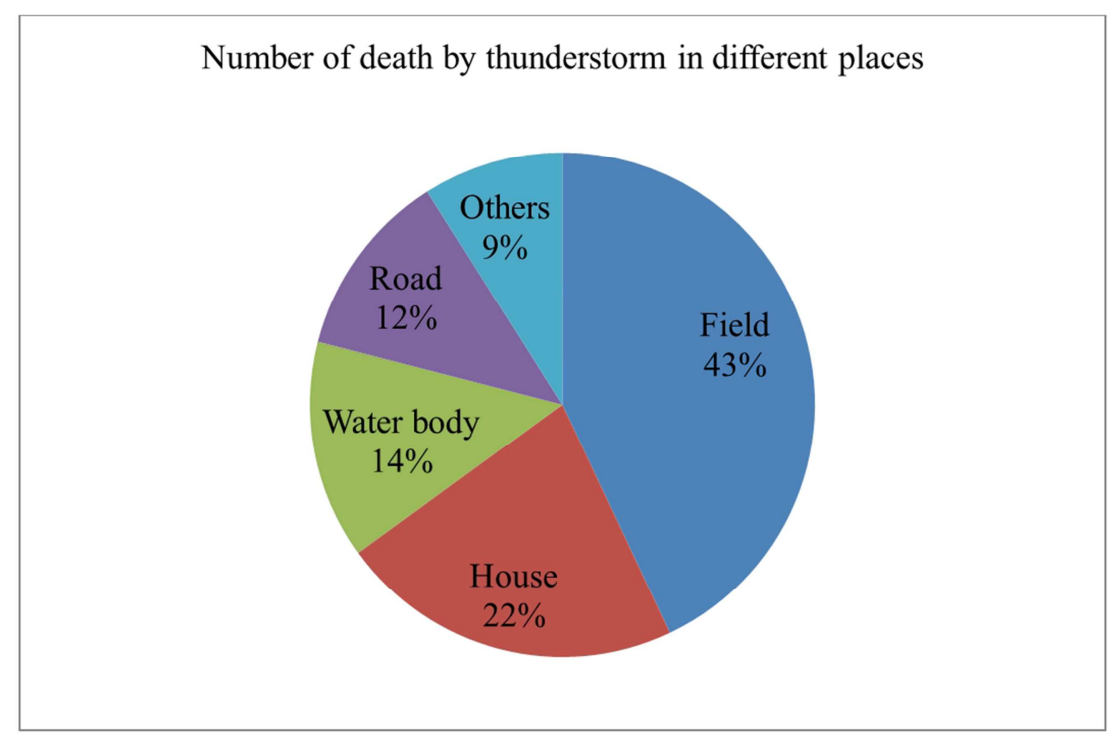

Source: The daily star reports (2010-2015)

Figure 2. Number of death by thunderstorm in different places.

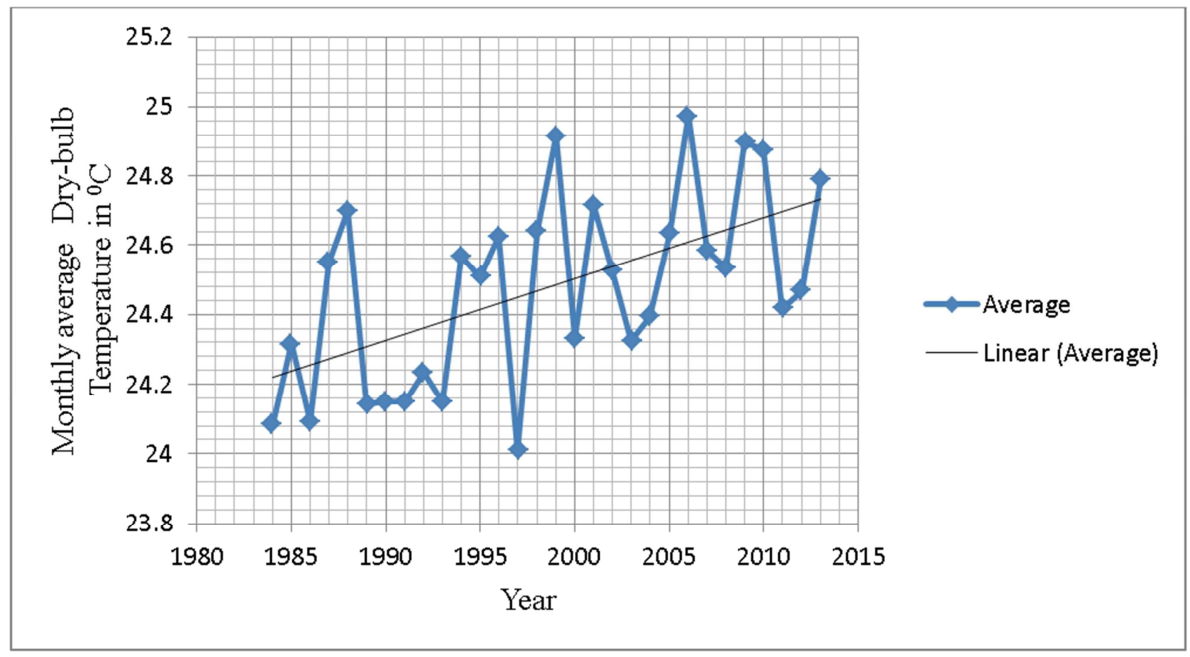

Figure 3. Monthly average dry-bulb temperature in Rangpur station.

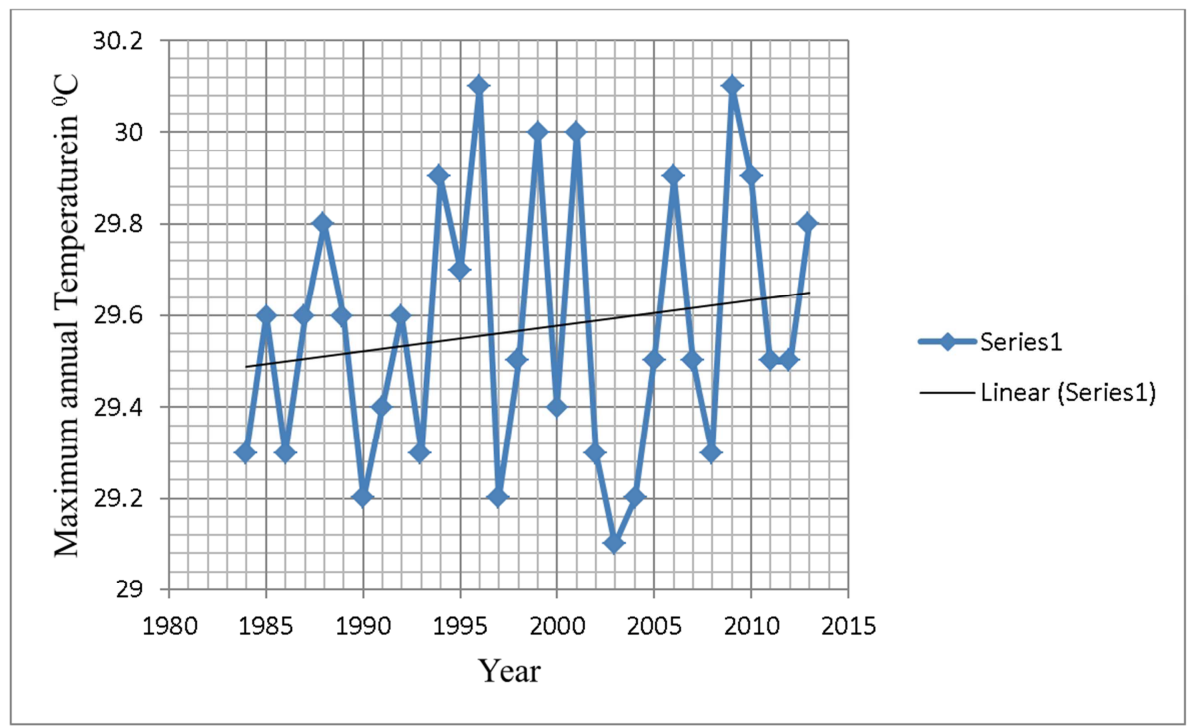

Figure 4. Maximum annual temperature in Rangpur station. 


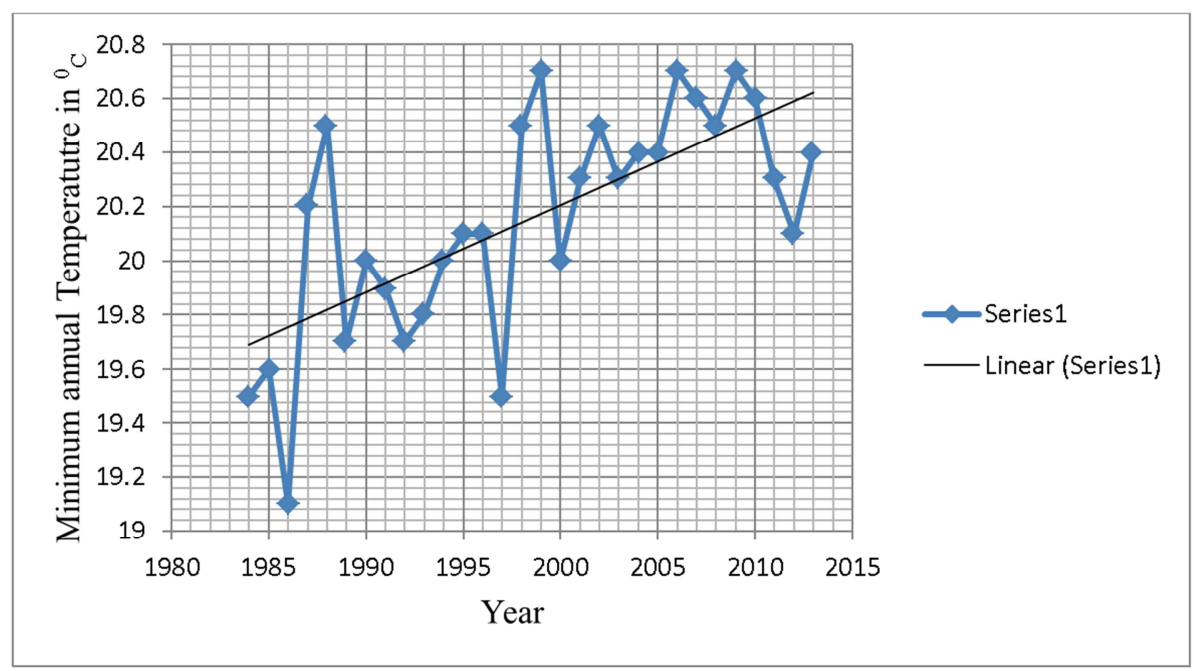

Figure 5. Minimum annual temperature in Rangpur station.

Dry-bulb temperature, maximum and minimum temperature of the Rangpur station in Figure (1-3). It was found that dry-bulb as well as maximum and minimum temperature is gradually increasing.

\section{Discussion}

From the analysis of the maximum temperature, minimum temperature and the dry-bulb temperature (which is the main indicator of occurring thunderstorm) it is seen in all cases that the temperature increased gradually in the last 29 years. The maximum annual temperature increased almost $1.2^{\circ} \mathrm{C}$, the minimum annual temperature increased almost $1^{\circ} \mathrm{C}$ and the dry-bulb temperature increased regularly. This gradually increased temperature makes huge dry air in summer season (May-June) which expands rapidly. As a result thunderstorm and lightening occurred due to lake of evaporation and cloud formation. It is also observed that lightning occurred minimum 2.5 kilometers to 3.0 kilometers away from the experimental earthen buildings and intensity was reduced very quickly with minimum damage. The onset of electrification occurred during or immediately after convective growth within the cloud. [11] Though thunderstorm brings some electrical and atmospheric blessing, it is more threatening for the people who work in the open field like cultivable lands, crops fields who use iron made tools for different purposes and also who are stay inside their living places having electronic devices.

\section{Conclusion}

Thunderstorm and lightning are the vital indicators of atmospheric physics. This paper provides empirical evidence that the temperature variation and lightening effect on the natural environment of Rangpur Region and also to the people. This indicates the various socio-environmental factors that played a crucial role influencing climate change of Bangladesh directly or by any other means. To save the people and natural resources government should take the initiatives to declare thunderstorm and lightening as natural disaster. Government should set up the minimum requirement for establishing the schools, colleges, apartments and any other infrastructures (where people stay for their safety) like earthen the buildings, having sufficient plants and water sources. Government also should take some prompt decision for implementation the policies before the summer season and enforce the people to obey them if necessary. Furthermore, more study and research should conduct so that mass awareness grown up to the mass people so that temperature remains in a optimal level to reduce the thunderstorm and lightening and to reduce the premature death of people and other resource animals to ensure better living environments in future after the declaration this incident as natural disaster.

\section{Conflict of Interest}

The authors declare that there is no conflict of interests regarding the publication of this paper.

\section{Acknowledgements}

Acknowledgment to Shah Azharul Islam, Dept. of Physics, A. S. M Imrul Shahed, dept. management in the Begum Rokeya University, Rangpur, Bangladesh

\section{References}

[1] A. B. M. Shamim UlHasan \& M. Zillurr Rahman. "Change in Temperature over Bangladesh Associated with Degrees of Global Warming", Asian Journal of Applied Science and Engineering, Volume 2, No 2 (2013) ISSN 2305-915X.

[2] Meteorological Office, Rangpur, Bangladesh.

[3] B K Chakravorti, "Earthquake forecasting in Bangladesh and its surrounding regions", European Scientific Journal June 2015 edition vol. 11, No. 18 ISSN: 1857 - 7881 (Print) e ISSN 1857- 7431 . 
[4] Ali A (1999). "Climate change impacts and adaptation assessment in Bangladesh. Space Research and Remote Sensing Organization (SPARRSO)", Agargaon, Sher-e Bangla Nagar, Dhaka 1207, Bangladesh, 12: 109-116.

[5] Asha Nath1, G K Manohar, K KDani and P C S Devara. "A study of lightning activity over land and oceanic regions of India", J. Earth Syst. Sci. 118, No. 5, October 2009, pp. 467481 .

[6] Shengmei Yang, Qiuwen Zhang, Yongzhi Zhang, Wenguang Wei. "Research on the Lightning Information Management System Based on GIS", Journal of software, vol. 7, NO. 8, August 2012.

[7] Yashvant Das. "Some Aspects of Thunderstorm over India during Pre-Monsoon Season: A Preliminary Report-I", Journal of Geosciences and Geomatics Vol. 3, No. 3, 2015, pp 68-78. doi: 10.12691/jgg-3-3-3.
[8] M Khatun, MA Islam, MA Haque- Khatun et al. (2016) "Studies of thunderstorms and lightning on human health, agriculture and fisheries in Mymensingh and Jamalpur district of Bangladesh.” Progressive Agriculture 27 (1): 57-63.

[9] Available online: https://ams.confex.com/ams/Annual2006/techprogram/paper 105612.htm.

[10] Jayaratne, E. R. Meteorl. Atmos. Phys. (1993) 52: 169. https://doi.org/10.1007/BF01031875.

[11] J. E. Dye, W. P. Winn, J. J. Jones and D. W. Baeed. The Electrification of New Mexico Thunderstorms Relationship between Precipitation Development and the Onset of Electrification”, Journal of geophysical research, vol. 94, no. D6, pages 8643-8656, June 20, 1989. 